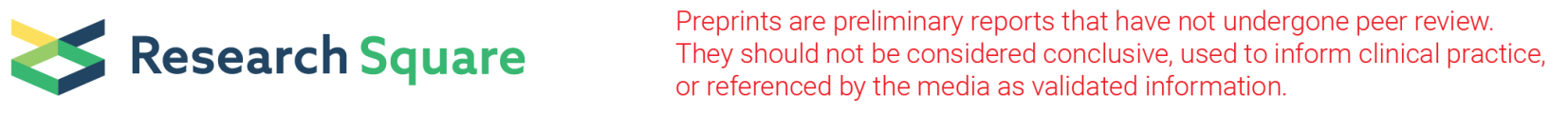

\title{
Effect of Phonophoresis On Patients With Knee Osteoarthritis: A Systematic Review And Meta-Analysis of Randomized Controlled Trials
}

\author{
Fu-An Yang \\ Taipei Medical University \\ Hung-Lun Chen \\ Taipei Medical University \\ Chih-Wei Peng \\ Taipei Medical University \\ Tsan-Hon Liou \\ Taipei Medical University

\section{Reuben Escorpizo} \\ University of Vermont \\ Hung-Chou Chen ( $\nabla$ 10462@s.tmu.edu.tw) \\ Taipei Medical University
}

\section{Research Article}

Keywords: knee, osteoarthritis, phonophoresis, therapeutic ultrasound, systematic review, meta-analysis

Posted Date: September 7th, 2021

DOI: https://doi.org/10.21203/rs.3.rs-799017/v1

License: (a) (1) This work is licensed under a Creative Commons Attribution 4.0 International License. Read Full License 


\section{Abstract}

Phonophoresis is an alternative treatment for knee osteoarthritis. However, evidence supporting the advantages of phonophoresis remains inconsistent. This systematic review and meta-analysis was conducted to illustrate the effect of phonophoresis. The PubMed, Cochrane Library, and Embase databases were searched for relevant studies from the date of their inception to 28 June, 2021. The eligibility criteria were: (1) randomized controlled trials (RCTs); (2) patients diagnosed as having knee osteoarthritis; (3) treatment with either phonophoresis or therapeutic ultrasound with placebo gels; and (4) reporting clinical and functional outcomes. Continuous variables are expressed as standardized mean differences (SMDs) with $95 \%$ confidence intervals (Cls). Analysis was performed using RevMan 5.3 software. The analysis included nine RCTs covering a total of 423 patients. The intervention group significantly outperformed the control group in visual analog scale score [SMD $=-0.65,95 \% \mathrm{Cl}(-1.04,-0.25), \mathrm{P}=0.001]$, Western Ontario and McMaster Universities Arthritis Index (WOMAC) score [SMD $=-0.71,95 \% \mathrm{Cl}(-1.26,-0.16), \mathrm{P}=0.01]$, and walk test score [SMD $=-0.67$, $95 \% \mathrm{Cl}(-1.21,-0.13), \mathrm{P}=0.02]$. As a result, phonophoresis might alleviate pain and improve function in the short term. Further highquality, large-scale RCTs are required to confirm the benefits.

\section{Introduction}

Knee osteoarthritis is characterized by the breakdown of articular cartilage over time. ${ }^{1,2}$ Although cartilage breakdown is the major disease characteristic, osteoarthritis affects all joint tissues, including the synovial membrane, which is usually associated with increased pain and joint dysfunction. ${ }^{2,3}$ Common clinical symptoms include knee pain with gradual onset and that worsens with activity, knee stiffness and swelling, pain after prolonged sitting or resting, and pain that worsens over time. ${ }^{4}$ Some studies have reported that approximately $13 \%$ of women and $10 \%$ of men aged 60 years and older have symptomatic knee osteoarthritis. ${ }^{5,6}$

Treatment initially involves nonsurgical modalities and progresses to surgical treatment once nonsurgical methods are no longer effective. ${ }^{4}$ These interventions do not alter the disease process, but they may substantially diminish pain and disability. ${ }^{7,8}$ According to several studies, self-management programs, muscle strengthening, low-impact aerobic exercises, neuromuscular education, and physical activity are recommended for patients with knee osteoarthritis. ${ }^{9-12}$ Oral pharmacological agents such as nonsteroidal antiinflammatory drugs (NSAIDs) and corticosteroids are also effective treatment for knee osteoarthritis. ${ }^{13-15}$ However, oral antiinflammatory drugs may increase the risks of gastrointestinal, renal, and other systemic toxicities. Topical gels are an alternative treatment with fewer complications compared with oral anti-inflammatory drugs. ${ }^{16-18}$

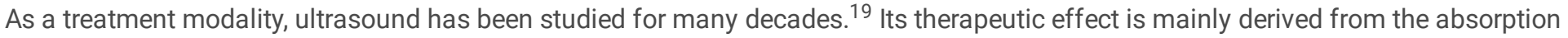
of mechanical energy and the production of heat in tissues. ${ }^{20}$ Phonophoresis involves the use of ultrasound to deliver therapeutic drugs by absorption and permeation through the skin. ${ }^{21}$ Phonophoresis with anti-inflammatory gels has been reported to treat pain and inflammation in many musculoskeletal conditions. ${ }^{22-25}$ Despite the wide use of phonophoresis, scientific evidence to support its use is insufficient, especially with regard to symptomatic knee osteoarthritis. Wu et al. conducted a systematic review and meta-analysis comparing the effects of therapeutic ultrasound for knee osteoarthritis. ${ }^{26} \mathrm{~A}$ subgroup analysis indicated that a phonophoresis ultrasound group exhibited lower visual analog scale (VAS) scores than a conventional nondrug ultrasound group. ${ }^{26}$ No significant differences were observed in Western Ontario and McMaster Universities Arthritis Index (WOMAC) scores. ${ }^{26}$ However, only three randomized controlled trials (RCTs) were included in that study. Moreover, according to our electronic database search, more RCTs have been published recently. Thus, we conducted this study to assess the effect of phonophoresis on knee osteoarthritis symptoms.

\section{Method}

This systematic review was registered prospectively on the International Prospective Register of Systematic Reviews (PROSPERO) database under the number CRD42021266126 on August 6, 2021.

Eligibility criteria

The eligibility criteria were as follows: (1) RCTs; (2) patients diagnosed as having knee osteoarthritis; (3) treatment with either phonophoresis or therapeutic ultrasound with placebo gel; and (4) reporting clinical outcomes including VAS score, WOMAC score, range of motion, and walk test scores. We excluded articles with only protocols and non-peer-reviewed articles, such as conference papers and letters to the editor. No language restriction was applied in our search strategy. 
The authors independently reviewed the literature, extracted data, and performed crosschecks in accordance with the Preferred Reporting Items for Systematic Reviews and Meta-Analyses guidelines. ${ }^{27}$ We searched electronic databases, namely PubMed, EMBASE, and Cochrane. We established group A based on phonophoresis and its synonyms; group B was formed using knee osteoarthritis and its synonyms. We intersected groups A and B to prepare our keywords for searching the aforementioned electronic databases (keywords are listed in the appendix). If available, RCTs were identified using the refined search functions of the databases. Additional articles were identified through a manual search of the reference lists of the relevant articles. The databases were searched from their inception to 28 June, 2021. Two reviewers independently reviewed the full texts of all potentially relevant articles to identify articles that met the eligibility criteria. Their decisions were then compared, and disagreements were resolved through discussion with a third reviewer.

Data items

The following data were obtained from each RCT: the characteristics of therapeutic ultrasound; the number and mean age of the participants in the intervention and control groups; the content of the gel; and outcome measurements.

Outcome measurements

The outcome measurements in this study were VAS score, WOMAC score, range of motion, and walk test scores. VAS is a measurement instrument of pain across a continuum of values; pain cannot be easily measured directly. ${ }^{28}$ Higher VAS scores indicate worse pain. WOMAC is a self-administered questionnaire widely applied for hip and knee osteoarthritis evaluations. ${ }^{29}$ Higher WOMAC scores denotes worse pain, stiffness, and physical function. Range of motion is the range through which a joint can be moved. ${ }^{30}$ The walk $^{2}$ tests included in this study were the 6-minute walk test, timed up and go test, 15-m walk test, and 20-m walk test. ${ }^{31,32}$

Risk-of-bias assessment

The risk of bias was assessed using the RoB 2 tool, a revision of the Cochrane risk-of-bias tool for RCTs, which is widely applied for assessing the quality of RCTs. ${ }^{33}$ The following domains were considered: (1) randomization process, (2) deviations from intended interventions, (3) missing outcome data, (4) outcome measurement, (5) selection of the reported result, and (6) overall bias. ${ }^{33}$ Following the Cochrane Handbook for Systematic Reviews of Interventions, the risk of bias was assessed by two independent reviewers. ${ }^{34}$ Disagreements between the reviewers were resolved through discussion and consultation with a third reviewer.

\section{Statistical analysis}

Statistical analyses were performed using RevMan 5.3 software, which was provided by the Cochrane Collaboration (https://training.cochrane.org/online-learning/core-software-cochrane-reviews/revman/revman-5-download). Continuous data were extracted as changes from baseline measurements. For data with missing standard deviations, the data were estimated by calculating correlation coefficients according to the Cochrane Handbook for Systematic Reviews of Interventions. ${ }^{34}$. The results with $\mathrm{P}<0.05$ were considered statistically significant. We used the $R$ test to objectively measure statistical heterogeneity, with $R \geq 75 \%$ indicating considerable heterogeneity. ${ }^{35} \mathrm{~A}$ random effects model was used in this meta-analysis. Continuous variables are expressed as standardized mean differences (SMDs) with 95\% confidence intervals (Cls). Because of the different contents of gels mentioned in the indicated studies, subgroup analysis was conducted based on different gel contents (corticosteroids, NSAIDs, and herbal gels).

A funnel plot was not used to test for publication bias because of the limited number of studies included in each analysis $(<10)$.

\section{Result}

Search Results

With the aforementioned search terms used, 2176 RCTs were initially retrieved. Of these, 633 duplicates were excluded using EndNote X9. ${ }^{36}$ Furthermore, 1491 studies that did not meet the inclusion criteria were excluded after their titles and abstracts were screened. The full texts of the remaining 52 papers were screened, revealing that 4 had the same study group, 9 were not yet published, 2 did not compare the intervention with placebo gel, 21 did not examine phonophoresis, $1 \mathrm{had}$ an additional intervention to the experimental 
intervention, 2 were not peer-reviewed articles, 2 compared phonophoresis with iontophoresis, and 2 did not mention standard deviations. Finally, nine articles were selected for meta-analysis (Fig. 1). ${ }^{37-45}$

Study Characteristics

The selected studies comprised 222 and 201 patients in the intervention and control groups, respectively. All selected RCTs are randomized, placebo-controlled trials. ${ }^{37-45}$ Two studies used corticosteroid gel, ${ }^{37,40}$ six used NSAID gel, ${ }^{39,41-45}$ and one used herbal gel. ${ }^{38}$ The main characteristics of the nine RCTs are summarized in Table 1.

Table 1

Characteristics of Selected Randomized Controlled Trials.

\begin{tabular}{|c|c|c|c|c|c|c|c|c|}
\hline \multirow[t]{2}{*}{ Author, year } & \multirow{2}{*}{$\begin{array}{l}\text { Therapeutic ultrasound } \\
\text { (mode/frequency/intensity/duration) }\end{array}$} & \multicolumn{3}{|c|}{ Intervention group } & \multicolumn{3}{|c|}{ Control group } & \multirow[t]{2}{*}{ Outcome } \\
\hline & & $\mathbf{n}$ & $\begin{array}{l}\text { Age, } \\
\text { mean } \\
\text { (SD) }\end{array}$ & Content of gel & $\mathbf{n}$ & $\begin{array}{l}\text { Age, } \\
\text { mean } \\
\text { (SD) }\end{array}$ & $\begin{array}{l}\text { Content } \\
\text { of gel }\end{array}$ & \\
\hline $\begin{array}{l}\text { Ahmed et al, } \\
2019^{37}\end{array}$ & $\begin{array}{l}\text { Continuous } / 1 \mathrm{MHz} / 1 \mathrm{Watt} / \mathrm{cm}^{2} / 10 \\
\min \end{array}$ & 23 & $\begin{array}{l}53.09 \\
(5.46)\end{array}$ & Dexamethasone & 23 & $\begin{array}{l}50.59 \\
(6.77)\end{array}$ & Placebo & $\begin{array}{l}\text { VAS, } \\
\text { WOMAC }\end{array}$ \\
\hline $\begin{array}{l}\text { Pinkaew et al, } \\
2019^{38}\end{array}$ & $\begin{array}{l}\text { Continuous/1 MHz/1 Watt/cm²/10 } \\
\min \end{array}$ & 20 & $\begin{array}{l}65.20 \\
(8.34)\end{array}$ & $\begin{array}{l}\text { Phyllanthus } \\
\text { amarus }\end{array}$ & 20 & $\begin{array}{l}64.30 \\
(9.71)\end{array}$ & Placebo & $\begin{array}{l}\text { VAS, Six- } \\
\text { minute } \\
\text { walk test }\end{array}$ \\
\hline $\begin{array}{l}\text { Zhao et al, } \\
2015^{39}\end{array}$ & $-/ 40 \mathrm{kHz} / 5000 \mathrm{~Pa} /-$ & 39 & $\begin{array}{l}59.4 \\
(8.9)\end{array}$ & Diclofenac & 19 & $\begin{array}{l}60.8 \\
(9.0)\end{array}$ & Placebo & $\begin{array}{l}\text { VAS, } \\
\text { WOMAC, } \\
\text { range of } \\
\text { motion }\end{array}$ \\
\hline $\begin{array}{l}\text { Oktayoğlu et } \\
\text { al, } 2014^{41}\end{array}$ & $\begin{array}{l}\text { Continuous } / 1 \mathrm{MHz} / 1.5 \text { Watt/cm²/10 } \\
\text { min }\end{array}$ & 20 & $\begin{array}{l}54.55 \\
(8.65)\end{array}$ & Diclofenac & 20 & $\begin{array}{l}55.05 \\
(10.08)\end{array}$ & Placebo & $\begin{array}{l}\text { VAS, } \\
\text { WOMAC }\end{array}$ \\
\hline $\begin{array}{l}\text { Toopchizadeh } \\
\text { et al, } 2014^{40}\end{array}$ & $-/-/ 1.5 \mathrm{Watt} / \mathrm{cm}^{2} / 5 \mathrm{~min}$ & 19 & $\begin{array}{l}54.6 \\
(6.23)\end{array}$ & Dexamethasone & 18 & $\begin{array}{l}56.95 \\
(7.33)\end{array}$ & Placebo & $\begin{array}{l}\text { VAS, } \\
\text { WOMAC, } \\
\text { timed up } \\
\text { and go } \\
\text { test }\end{array}$ \\
\hline $\begin{array}{l}\text { Boyaci et al, } \\
2013^{43}\end{array}$ & $\begin{array}{l}\text { Continuous/1 MHz/1.5 Watt/cm²/8 } \\
\min \end{array}$ & 33 & $\begin{array}{l}52.45 \\
(4.80)\end{array}$ & Ketoprofen & 33 & $\begin{array}{l}52.58 \\
(7.27)\end{array}$ & Placebo & $\begin{array}{l}\text { VAS, } \\
\text { WOMAC, } \\
15 \\
\text { metres } \\
\text { walking } \\
\text { time }\end{array}$ \\
\hline $\begin{array}{l}\text { Luksurapan } \\
\text { et al, } 2013^{42}\end{array}$ & $\begin{array}{l}\text { Continuous/1 MHz/1 Watt/cm²/10 } \\
\text { min }\end{array}$ & 23 & $\begin{array}{l}59.83 \\
(9.88)\end{array}$ & Piroxicam & 23 & $\begin{array}{l}58.00 \\
(11.22)\end{array}$ & Placebo & $\begin{array}{l}\text { VAS, } \\
\text { WOMAC }\end{array}$ \\
\hline $\begin{array}{l}\text { Akinbo et al, } \\
2011^{44}\end{array}$ & Continuous/1 MHz/1 Watt/cm²/- & 15 & $\begin{array}{l}64.29 \\
(19.83)\end{array}$ & Diclofenac & 15 & $\begin{array}{l}64.92 \\
(10.52)\end{array}$ & Placebo & $\begin{array}{l}\text { WOMAC, } \\
\text { range of } \\
\text { motion, } \\
20 \\
\text { meters } \\
\text { walking } \\
\text { time }\end{array}$ \\
\hline $\begin{array}{l}\text { Kozanoglu et } \\
\text { al, } 2003^{45}\end{array}$ & $\begin{array}{l}\text { Continuous/1 MHz/1 Watt/cm²/5 } \\
\text { min }\end{array}$ & 30 & $\begin{array}{l}60.3 \\
(9.2)\end{array}$ & Ibuprofen & 30 & $\begin{array}{l}59.4 \\
(8.9)\end{array}$ & Placebo & $\begin{array}{l}\text { VAS, } \\
\text { WOMAC, } \\
20 \\
\text { metres } \\
\text { walking } \\
\text { time, } \\
\text { range of } \\
\text { motion }\end{array}$ \\
\hline
\end{tabular}

Risk-of-Bias Assessment 
Two reviewers assessed the quality of the selected RCTs by using RoB $2 .{ }^{33}$ Fig. 2 illustrates the risk of bias for each study. Nine studies had a low risk associated with the randomization process. ${ }^{37-45}$ Four studies exhibited some concerns regarding the risk associated with deviations from the intended intervention, ${ }^{41,43-45}$ whereas five studies exhibited a low risk. ${ }^{37-40,42}$ Eight studies had a low risk related to missing outcome data, ${ }^{37,38,40-45}$ and some concerns were noted in one study. ${ }^{39}$ Regarding outcome measurements, five studies exhibited a low risk, ${ }^{37,38,40,42,43}$ and four exhibited some concerns. ${ }^{39,41,44,45}$ Regarding the selection of reported results, all nine studies exhibited a low risk. ${ }^{37-45}$ The overall risk of bias was low for six studies ${ }^{37-40,42,43}$ and uncertain for three studies. ${ }^{41,44,45}$

VAS scores

VAS scores were reported in eight studies, ${ }^{37-43,45}$ which included 207 patients in the experimental group and 186 in the control group. The heterogeneity of the studies was moderate to high $(R=72 \%, P=0.0009)$. VAS scores were significantly lower in the experimental group than in the control group $[S M D=-0.65,95 \% \mathrm{Cl}(-1.04,-0.25), P=0.001]$ (Fig. 3). Subgroup analysis revealed a significant difference in VAS scores between the experimental and control group participants receiving NSAID gel [5 RCTs ${ }^{39,41-43,45}$ with 145 patients in the experimental group and 125 in the control group, $\mathrm{SMD}=-0.53,95 \% \mathrm{Cl}(-1.02,-0.05), \mathrm{P}=0.03$ ] or herbal gel [one $\mathrm{RCT}{ }^{38}$ with 20 patients in the experimental group and 20 in the control group, $S M D=-1.56,95 \% \mathrm{Cl}(-2.28,-0.85), P<0.0001]$ but not corticosteroid gel $\left[2 \mathrm{RCTs}^{37,40}\right.$ with 42 patients in the experimental group and 41 in the control group, $\mathrm{SMD}=-0.53,95 \% \mathrm{Cl}(-1.13$, $0.07), P=0.09]$.

\section{WOMAC scores}

WOMAC scores were reported in eight studies, ${ }^{37,39-45}$ which included 202 patients in the experimental group and 181 in the control group. The heterogeneity of the studies was high $(R=84 \%, \mathrm{P}<0.00001)$. WOMAC scores were significantly lower in the experimental group than in the control group [SMD $=-0.71,95 \% \mathrm{Cl}(-1.26,-0.16), \mathrm{P}=0.01]$ (Fig. 4). Subgroup analysis revealed significant differences in WOMAC scores between the experimental and control group participants receiving corticosteroid gel [2 RCTs ${ }^{37,40}$ with 42 patients in the experimental group and 41 in the control group, $\mathrm{SMD}=-0.89,95 \% \mathrm{Cl}(-1.34,-0.44), \mathrm{P}=0.0001]$, but the same was not true for NSAID gel [6 RCTs ${ }^{39,41-45}$ with 160 patients in the experimental group and 140 in the control group, $\mathrm{SMD}=-0.66,95 \% \mathrm{Cl}(-$ $1.37,0.05), P=0.07]$.

Because of the high heterogeneity found, sensitivity analysis was conducted. Two studies were excluded. ${ }^{44,45}$ Sensitivity analysis revealed acceptable heterogeneity $(R=68 \%, P=0.008)$. WOMAC scores remained significantly lower in the experimental group than in the control group [SMD $=-0.62,95 \% \mathrm{Cl}(-1.05,-0.19), \mathrm{P}=0.004]$.

Range of Motion

Range of motion was reported in three studies, ${ }^{39,44,45}$ which included 84 patients in the experimental group and 64 in the control group. These three studies all used NSAID gel. The heterogeneity of the studies was high $(R=90 \%, P<0.0001)$. Range of motion was not significantly greater in the experimental group than in the control group $[S M D=1.07,95 \% \mathrm{Cl}(-0.09,2.00), P=0.07]$. (Fig. 5).

Walk tests

The results of walk tests were reported in five studies, ${ }^{38,40,43-45}$ which included 117 patients in the experimental group and 116 in the control group. The heterogeneity of the studies was moderate to high $(R=74 \%, P=0.004)$. Walk test outcomes were significantly favorable in the experimental group than in the control group [SMD $=-0.67,95 \% \mathrm{Cl}(-1.21,-0.13), P=0.02]$ (Fig. 6). Subgroup analysis revealed significant differences in walk test scores between the experimental and control group participants receiving herbal gel [1 $\mathrm{RCT}^{38}$ with 20 patients in the experimental group and 20 in the control group, $\left.\mathrm{SMD}=-1.41,95 \% \mathrm{Cl}(-2.11,-0.71), \mathrm{P}<0.0001\right]$ but the same was not true for those receiving corticosteroid gel [ $1 \mathrm{RCT}^{40}$ with 19 patients in the experimental group and 18 in the control group, $\mathrm{SMD}=-0.25,95 \% \mathrm{Cl}(-0.90,0.39), \mathrm{P}=0.44$ ] or NSAID gel [three RCTs ${ }^{43-45}$ with 78 patients in the experimental group and 78 in the control group, $\mathrm{SMD}=-0.57,95 \% \mathrm{Cl}(-1.27,0.12), \mathrm{P}=0.10]$.

Adverse Events

Of the nine selected RCTs, four reported whether adverse effects occurred. ${ }^{38,39,42,45}$ No adverse events were observed in these studies, indicating that the interventions were well tolerated by the participants.

Page 5/13 


\section{Discussion}

Knee osteoarthritis is a degenerative joint cartilage condition. ${ }^{1,2}$ Its common clinical symptoms include knee pain that is gradual in onset and that worsens with activity, knee stiffness and swelling, pain after prolonged sitting or resting, and pain that worsens over time. ${ }^{4}$ Topical anti-inflammatory drugs are an alternative treatment choice, with fewer gastrointestinal complications relative to oral drugs. ${ }^{16-18}$

In phonophoresis, ultrasound is used to deliver therapeutic drugs by absorption and permeation through the skin. ${ }^{21}$ Despite its wide usage, supporting scientific evidence is insufficient, especially with regard to symptomatic knee osteoarthritis. Thus, we conducted this study to assess the effect of phonophoresis on knee osteoarthritis symptoms. Our analysis revealed significant intergroup differences favoring phonophoresis according to VAS, WOMAC, and walk test scores. Subgroup analysis revealed significant differences favoring phonophoresis with NSAID gel according to VAS and walk test scores, whereas it revealed significant differences favoring corticosteroid gel according to WOMAC scores.

Therapeutic ultrasound is a deep-heating modality used in physical therapy. ${ }^{41}$ According to Rao et al., therapeutic ultrasound is generated by a transducer that converts electrical energy to ultrasound by using the piezoelectric principle. ${ }^{46}$ Although the exact mechanism of its effect is not well known, the effect may be composed of two components, namely thermal effect and nonthermal effect. ${ }^{47}$ In terms of thermal effects, therapeutic ultrasound induces muscle relaxation, increases connective tissue extensibility, and increases local blood flow, all of which induce tissue regeneration and reduce inflammation. ${ }^{41,47}$ Nonthermal ultrasound effects are related to acoustic cavitation with resultant increases in cell permeability, which is a potential pain relief mechanism. ${ }^{47}$ Phonophoresis is the use of ultrasound to deliver therapeutic drugs by absorption and permeation through the skin. ${ }^{21}$ The advantage of therapeutic ultrasound is that it may promote the transdermal penetration of therapeutic drugs. ${ }^{42,45}$ Moreover, this method is noninvasive and has a minimal risk of adverse effects associated with systemic administration of anti-inflammatory drugs, and it combines the therapeutic effects of ultrasound and topical drugs. ${ }^{42}$ Phonophoresis accounts for up to $30 \%$ of physiotherapy visits in some medical centers. ${ }^{44}$

Recently, gels with different contents have been made available for phonophoresis. The common gels are corticosteroid and NSAID gels. In the selected RCTs, two focused on corticosteroid gels, ${ }^{37,40}$ six focused on NSAID gels, ${ }^{39,41-45}$ and one focused on herbal gels. ${ }^{38}$ The two studies that used corticosteroid gels used dexamethasone gels. ${ }^{37,40}$ In the six RCTs that focused on NSAID gels, three used diclofenac gels, ${ }^{39,41,44}$ one used ibuprofen gel, ${ }^{45}$ one used ketoprofen gel, ${ }^{43}$ and one used piroxicam gel. ${ }^{42}$ The herbal gel was Phyllanthus amarus gel. ${ }^{38}$ Although each type of gel had anti-inflammatory effects; their chemical properties (e.g., their permeability to the tissue through ultrasound waves) differed, as reported by Akinbo et al. ${ }^{44}$ In a literature review, Srbely et al. indicated that the depth of penetration of a drug depends on its mass (which is inversely proportional to its molecular weight). ${ }^{48}$. Molecular weight is different from the contents of gels discussed in the selected RCTs. Dexamethasone has a high molecular weight; thus, it has a low drug mass and high permeability through ultrasound waves. The aforementioned reasons may explain why patients in the corticosteroid gel subgroup exhibited greater improvements in some outcomes than those in the NSAID gel subgroup. ${ }^{44}$ Thus, drug selection for phonophoresis seems to be as important as ultrasound parameters treatment success. ${ }^{37}$

According to Byl et al., the diffusion of topically applied drugs through the skin can also be enhanced by preheating the skin to increase kinetic energy. ${ }^{49}$ In our selected RCTs, three studies followed this principle. ${ }^{40,44,45}$ The application of heat before treatment may have influenced the results in these studies. On the basis of our analysis, the outcomes when preheating was applied were controversial. Some studies showed improved outcomes, whereas others reported no differences when compared with outcomes without preheating application. Therefore, the exact effects of preheating the skin require further investigation.

Regarding WOMAC scores, study heterogeneity was high $(R=84 \%, P<0.00001)$. For this reason, sensitivity analysis was conducted. According to the Cochrane Handbook for Systematic Reviews of Interventions, heterogeneity may arise due to the presence of one or two outlying studies with results that conflict with those of the remaining studies. ${ }^{34}$ If an obvious reason for the outlying result is apparent, the study might be removed with more confidence. ${ }^{34}$ In the selected studies mentioning WOMAC score as an outcome, both Akinbo et al. and Kozanoglu et al. applied preheating on the treatment site before treatment. ${ }^{44,45}$ They followed the principle of Byl et al. ${ }^{49}$ However, this application may influence treatment outcomes. As a result, these two outliners ${ }^{44,45}$ were excluded from the analysis. After these two studies were excluded, heterogeneity became acceptable $(R=68 \%, P=0.008)$. Moreover, WOMAC scores remained significantly lower in the experimental group than in the control group [SMD $=-0.62,95 \% \mathrm{Cl}(-1.05,-0.19), P=0.004]$. 
In a systematic review and meta-analysis, Wu et al. assessed the effectiveness and safety of different therapeutic ultrasound methods. ${ }^{26}$ In the subanalysis of phonophoresis, three RCTs were examined. ${ }^{42,43,45}$ The results revealed that the phonophoresis ultrasound group exhibited lower VAS scores [SMD $=-0.41,95 \% \mathrm{Cl}(-0.71,-0.10), \mathrm{P}=0.009]$ but showed no significant difference in WOMAC scores [SMD $=-0.16,95 \% \mathrm{Cl}(-0.46,0.14), \mathrm{P}=0.30]$. In recent years, studies on phonophoresis have been conducted. ${ }^{37-45} \mathrm{We}$ examined the effect of phonophoresis on patients with knee osteoarthritis. We focused on the outcomes of VAS score, WOMAC score, range of motion, and walk tests and found that phonophoresis effectively improved such outcome measures.

This systematic review and meta-analysis has several strengths. First, this is the first meta-analysis of RCTs that focused on the effects of phonophoresis in patients with knee osteoarthritis, with adequate evidence provided. Second, several studies are ongoing in this field according to our electronic database search. Thus, the study results will serve as a reference for future studies. Third, multiple major databases were used for the selection of RCTs, without language restrictions. Fourth, the data and quality of selected studies were extracted and assessed, respectively, by at least two reviewers through a group consensus approach.

Our study had several limitations, which might limit the generalization of our results. First, heterogeneity was moderate to high for some outcomes. This might be because of varying disease severity, symptom durations, patient characteristics, and treatment protocols. Thus, further studies are required to establish a standardized treatment protocol. Second, different gel contents such as lidocaine or capsaicin that could be applied in the experimental group were not studied. Future studies should examine different contents of gel and measure their effects. Third, some studies did not mention blinding to therapeutics and the blinding of patients or assessors. Hence, some concerns regarding risk of bias may persist. Fourth, in the selected RCTs, follow-up durations were mostly short. One study had a 1-month follow-up, ${ }^{39}$ and one study had a 3-month follow-up; ${ }^{41}$ others provided follow-up data within 1 week after intervention. ${ }^{37,38,40,42-45}$ Thus, more high-quality large-scale RCTs with long-term follow-ups are required to overcome these limitations.

\section{Conclusion}

This is the first meta-analysis of RCTs that focused on the effect of phonophoresis in patients with knee osteoarthritis and provided adequate evidence. According to our analysis, phonophoresis might improve pain and functions in the short term. Furthermore, no adverse events were noted in the selected studies. Phonophoresis is a treatment option for patients with knee osteoarthritis. However, further high-quality, large-scale, and long-follow-up-period RCTs are required to confirm the benefit and long-term effects of this intervention.

\section{Declarations}

\section{Acknowledgements}

This manuscript was edited by Wallace Academic Editing.

\section{Author contributions}

Fu-An Yang and Hung-Lun Chen conceptualized and designed the study and drafted the manuscript. Hung-Chou Chen critically revised the manuscript for intellectual content. Chih-Wei Peng, and Tsan-Hon Liou conducted a comprehensive search for articles that met the eligibility criteria. Fu-An Yang and Hung-Lun Chen extracted the relevant data and assessed the quality of the selected trials. Hung-Chou Chen, Reuben Escorpizo and Tsan-Hon Liou provided statistical expertise, analyzed and interpreted the data, and submitted the manuscript. Fu-An Yang and Hung-Lun Chen contributed equally to this study.

\section{Funding}

This research received no specific grant from any funding agency in the public, commercial, or not-for-profit sectors.

\section{Declaration of Conflicting Interests}

The authors have no conflicts of interest to declare.

\section{References}


1 Masiero, S. et al. The role of thermal balneotherapy in the treatment of obese patient with knee osteoarthritis. International Journal of Biometeorology 62, 243-252, doi:10.1007/s00484-017-1445-7 (2018).

2 Scanzello, C. R. \& Goldring, S. R. The role of synovitis in osteoarthritis pathogenesis. Bone 51, 249-257, doi:10.1016/j.bone.2012.02.012 (2012).

3 Kapoor, M., Martel-Pelletier, J., Lajeunesse, D., Pelletier, J. P. \& Fahmi, H. Role of proinflammatory cytokines in the pathophysiology of osteoarthritis. Nat Rev Rheumatol 7, 33-42, doi:10.1038/nrrheum.2010.196 (2011).

4 Hsu, H. \& Siwiec, R. M. in StatPearls (StatPearls Publishing

Copyright (C) 2021, StatPearls Publishing LLC., 2021).

5 Magnusson, K., Turkiewicz, A. \& Englund, M. Nature vs nurture in knee osteoarthritis - the importance of age, sex and body mass index. Osteoarthritis Cartilage 27, 586-592, doi:10.1016/j.joca.2018.12.018 (2019).

6 Li, J. S. et al. Weight loss changed gait kinematics in individuals with obesity and knee pain. Gait Posture 68, 461-465, doi:10.1016/j.gaitpost.2018.12.031 (2019).

7 Martel-Pelletier, J. et al. A new decision tree for diagnosis of osteoarthritis in primary care: international consensus of experts. Aging Clin Exp Res 31, 19-30, doi:10.1007/s40520-018-1077-8 (2019).

8 Aweid, O., Haider, Z., Saed, A. \& Kalairajah, Y. Treatment modalities for hip and knee osteoarthritis: A systematic review of safety. J Orthop Surg (Hong Kong) 26, 2309499018808669, doi:10.1177/2309499018808669 (2018).

9 Jevsevar, D. S. Treatment of Osteoarthritis of the Knee: Evidence-Based Guideline, 2nd Edition. JAAOS - Journal of the American Academy of Orthopaedic Surgeons 21 (2013).

10 Fransen, M. et al. Exercise for osteoarthritis of the knee: a Cochrane systematic review. Br J Sports Med 49, 1554-1557, doi:10.1136/bjsports-2015-095424 (2015).

11 Hammer, N. M., Bieler, T., Beyer, N. \& Midtgaard, J. The impact of self-efficacy on physical activity maintenance in patients with hip osteoarthritis - a mixed methods study. Disabil Rehabil 38, 1691-1704, doi:10.3109/09638288.2015.1107642 (2016).

12 Zhang, W. et al. OARSI recommendations for the management of hip and knee osteoarthritis: part III: Changes in evidence following systematic cumulative update of research published through January 2009. Osteoarthritis Cartilage 18, 476-499, doi:10.1016/j.joca.2010.01.013 (2010).

13 Jevsevar, D. S. et al. Mixed Treatment Comparisons for Nonsurgical Treatment of Knee Osteoarthritis: A Network Meta-analysis. JAAOS - Journal of the American Academy of Orthopaedic Surgeons 26, 325-336, doi:10.5435/jaaos-d-17-00318 (2018).

14 da Costa, B. R. et al. Effectiveness of non-steroidal anti-inflammatory drugs for the treatment of pain in knee and hip osteoarthritis: a network meta-analysis. Lancet 390, e21-e33, doi:10.1016/s0140-6736(17)31744-0 (2017).

15 Adatia, A., Rainsford, K. D. \& Kean, W. F. Osteoarthritis of the knee and hip. Part II: therapy with ibuprofen and a review of clinical trials. J Pharm Pharmacol 64, 626-636, doi:10.1111/j.2042-7158.2012.01456.x (2012).

16 Wolff, D. G., Christophersen, C., Brown, S. M. \& Mulcahey, M. K. Topical nonsteroidal anti-inflammatory drugs in the treatment of knee osteoarthritis: a systematic review and meta-analysis. Phys Sportsmed, 1-11, doi:10.1080/00913847.2021.1886573 (2021).

17 Derry, S., Conaghan, P., Da Silva, J. A., Wiffen, P. J. \& Moore, R. A. Topical NSAIDs for chronic musculoskeletal pain in adults. Cochrane Database Syst Rev 4, Cd007400, doi:10.1002/14651858.CD007400.pub3 (2016).

18 Rodriguez-Merchan, E. C. Topical therapies for knee osteoarthritis. Postgrad Med 130, 607-612, doi:10.1080/00325481.2018.1505182 (2018).

19 Baker, K. G., Robertson, V. J. \& Duck, F. A. A review of therapeutic ultrasound: biophysical effects. Phys Ther 81, 1351-1358 (2001). 

1448, doi:10.1093/pm/pnz102 (2019).

21 Souza, J., Meira, A., Volpato, N. M., Mayorga, P. \& Gottfried, C. Effect of Phonophoresis on Skin Permeation of Commercial Antiinflammatory Gels: Sodium Diclofenac and Ketoprofen. Ultrasound in Medicine \& Biology 39, 1623-1630, doi:https://doi.org/10.1016/j.ultrasmedbio.2013.02.009 (2013).

22 Yildiz, N. et al. Comparison of ultrasound and ketoprofen phonophoresis in the treatment of carpal tunnel syndrome. J Back Musculoskelet Rehabil 24, 39-47, doi:10.3233/bmr-2011-0273 (2011).

23 Deshpande, M. M. \& Patil, C. B. Heel pain and phonophoresis. J Indian Med Assoc 108, 365 (2010).

24 Ay, S., Doğan, S. K., Evcik, D. \& Başer, O. C. Comparison the efficacy of phonophoresis and ultrasound therapy in myofascial pain syndrome. Rheumatol Int 31, 1203-1208, doi:10.1007/s00296-010-1419-0 (2011).

25 Vlak, T. [Comparative study of the efficacy of ultrasound and sonophoresis in the treatment of painful shouder syndrome]. Reumatizam 46, 5-11 (1999).

26 Wu, Y. et al. Effects of therapeutic ultrasound for knee osteoarthritis: a systematic review and meta-analysis. Clinical Rehabilitation 33, 1863-1875, doi:10.1177/0269215519866494 (2019).

27 Moher, D., Liberati, A., Tetzlaff, J. \& Altman, D. G. Preferred reporting items for systematic reviews and meta-analyses: the PRISMA statement. Ann Intern Med 151, 264-269, w264, doi:10.7326/0003-4819-151-4-200908180-00135 (2009).

28 Wewers, M. E. \& Lowe, N. K. A critical review of visual analogue scales in the measurement of clinical phenomena. Res Nurs Health 13, 227-236, doi:10.1002/nur.4770130405 (1990).

29 Gandek, B. Measurement properties of the Western Ontario and McMaster Universities Osteoarthritis Index: a systematic review. Arthritis Care Res (Hoboken) 67, 216-229, doi:10.1002/acr.22415 (2015).

30 Gajdosik, R. L. \& Bohannon, R. W. Clinical measurement of range of motion. Review of goniometry emphasizing reliability and validity. Phys Ther 67, 1867-1872, doi:10.1093/ptj/67.12.1867 (1987).

31 Enright, P. L. The six-minute walk test. Respir Care 48, 783-785 (2003).

32 Podsiadlo, D. \& Richardson, S. The timed "Up \& Go": a test of basic functional mobility for frail elderly persons. J Am Geriatr Soc 39, 142-148, doi:10.1111/j.1532-5415.1991.tb01616.x (1991).

33 Higgins, J. P. T. et al. The Cochrane Collaboration's tool for assessing risk of bias in randomised trials. BMJ 343, d5928, doi:10.1136/bmj.d5928 (2011).

34 Higgins JPT TJ, C. J., Cumpston M, Li T, Page MJ, Welch VA (editors). Cochrane Handbook for Systematic Reviews of Interventions version 6.2 (updated February 2021). Cochrane, 2021. Available from www.training.cochrane.org/handbook. .

35 Melsen, W. G., Bootsma, M. C., Rovers, M. M. \& Bonten, M. J. The effects of clinical and statistical heterogeneity on the predictive values of results from meta-analyses. Clin Microbiol Infect 20, 123-129, doi:10.1111/1469-0691.12494 (2014).

36 EndNote v. EndNote X9 (Clarivate P, P., 2013).

37 Said Ahmed, M., Boles Saweeres, E., Abdelkader, N., Abdelmajeed, S. \& Fares, A. Improved pain and function in knee osteoarthritis with dexamethasone phonophoresis: a randomized controlled trial. Indian journal of orthopaedics 53, 700-707, doi:10.4103/ortho.IJOrtho_639_18 (2019).

38 Pinkaew, D., Kiattisin, K., Wonglangka, K. \& Awoot, P. Phonophoresis of Phyllanthus amarus nanoparticle gel improves functional capacity in individuals with knee osteoarthritis: a randomized controlled trial. Journal of bodywork and movement therapies, doi:10.1016/j.jbmt.2019.04.013 (2019). 

treatment of knee osteoarthritis: a double-blind, randomized, placebo-controlled clinical trial. Journal of traditional chinese medicine = chung i tsa chih ying wen pan 36, 613-617, doi:10.1016/s0254-6272(16)30080-2 (2016).

40 Toopchizadeh, V., Javadi, R. \& Sadat, B. E. Therapeutic efficacy of dexamethasone phonophoresis on symptomatic knee osteoarthritis in elderly women. International journal of women's health and reproduction sciences 2, 168-177, doi:10.15296/ijwhr.2014.25 (2014).

41 Oktayoglu, P. et al. Comparison of the efficacy of phonophoresis and conventional ultrasound therapy in patients with primary knee osteoarthritis. Erciyes tip dergisi 36, 11-18, doi:10.5152/etd.2013.64 (2014).

42 Luksurapan, W. \& Boonhong, J. Effects of phonophoresis of piroxicam and ultrasound on symptomatic knee osteoarthritis. Archives of physical medicine and rehabilitation 94, 250-255, doi:10.1016/j.apmr.2012.09.025 (2013).

43 Boyaci, A., Tutoglu, A., Boyaci, N., Aridici, R. \& Koca, I. Comparison of the efficacy of ketoprofen phonophoresis, ultrasound, and short-wave diathermy in knee osteoarthritis. Rheumatology internationa/33, 2811-2818, doi:10.1007/s00296-013-2815-z (2013).

44 Akinbo, S., Owoeye, O. \& Adesegun, S. Comparison of the therapeutic efficacy of diclofenac sodium and methyl salicylate phonophoresis in the management of knee osteoarthritis. Turkish journal of rheumatology 26, 111-119, doi:10.5606/tjr.2011.017 (2011).

45 Kozanoglu, E., Basaran, S., Guzel, R. \& Guler-Uysal, F. Short term efficacy of ibuprofen phonophoresis versus continuous ultrasound therapy in knee osteoarthritis. Swiss medical weekly 133, 333-338 (2003).

46 Rao, R. \& Nanda, S. Sonophoresis: recent advancements and future trends. J Pharm Pharmaco/ 61, 689-705, doi:10.1211/jpp.61.06.0001 (2009).

47 Robertson, V. J. \& Baker, K. G. A review of therapeutic ultrasound: effectiveness studies. Phys Ther 81, 1339-1350 (2001).

48 Srbely, J. Z. Ultrasound in the management of osteoarthritis: part I: a review of the current literature. J Can Chiropr Assoc 52, 3037 (2008).

49 Byl, N. N. The use of ultrasound as an enhancer for transcutaneous drug delivery: phonophoresis. Phys Ther 75, 539-553, doi:10.1093/ptj/75.6.539 (1995).

\section{Figures}




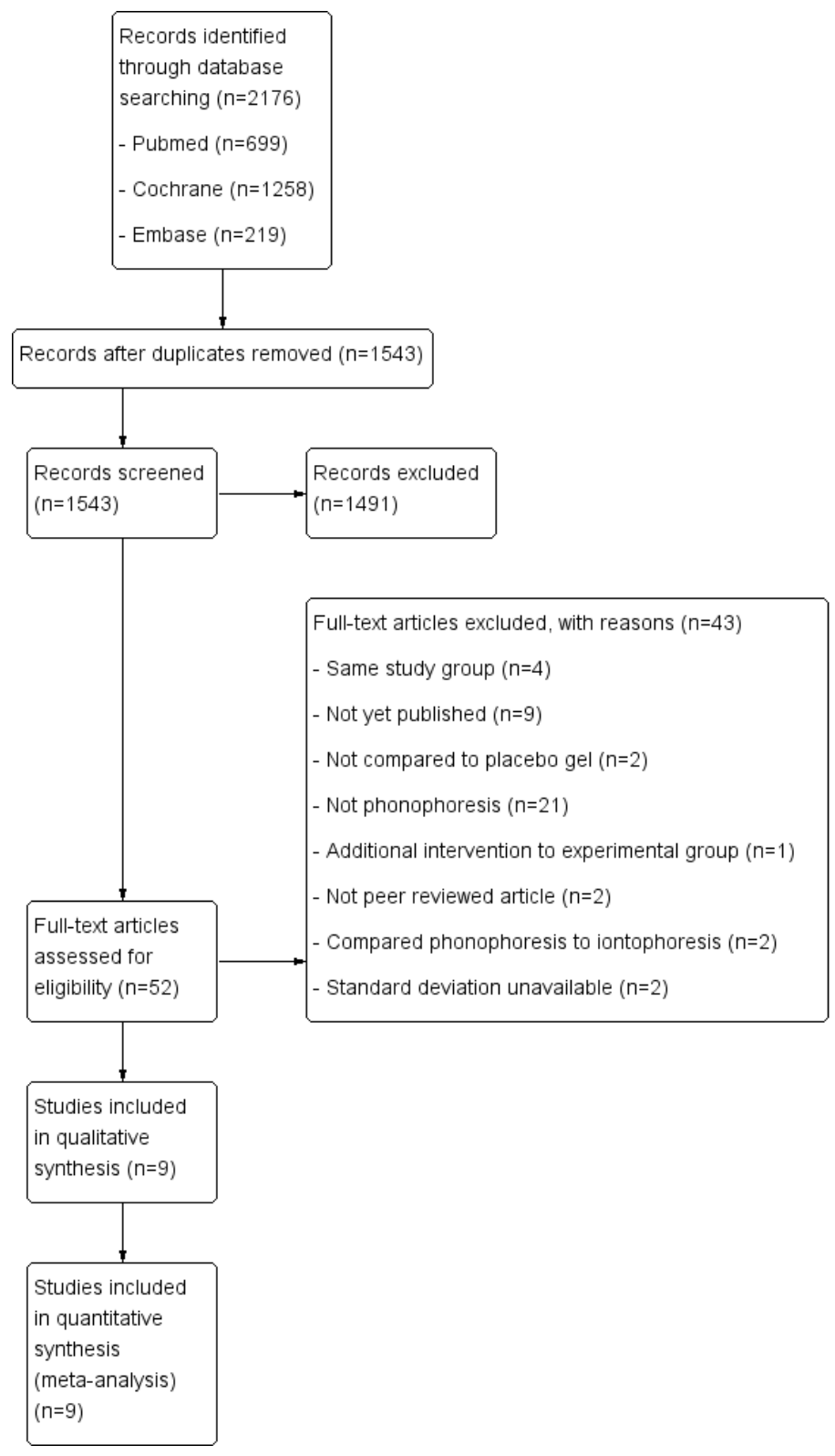

\section{Figure 1}

Flowchart of article selection. 


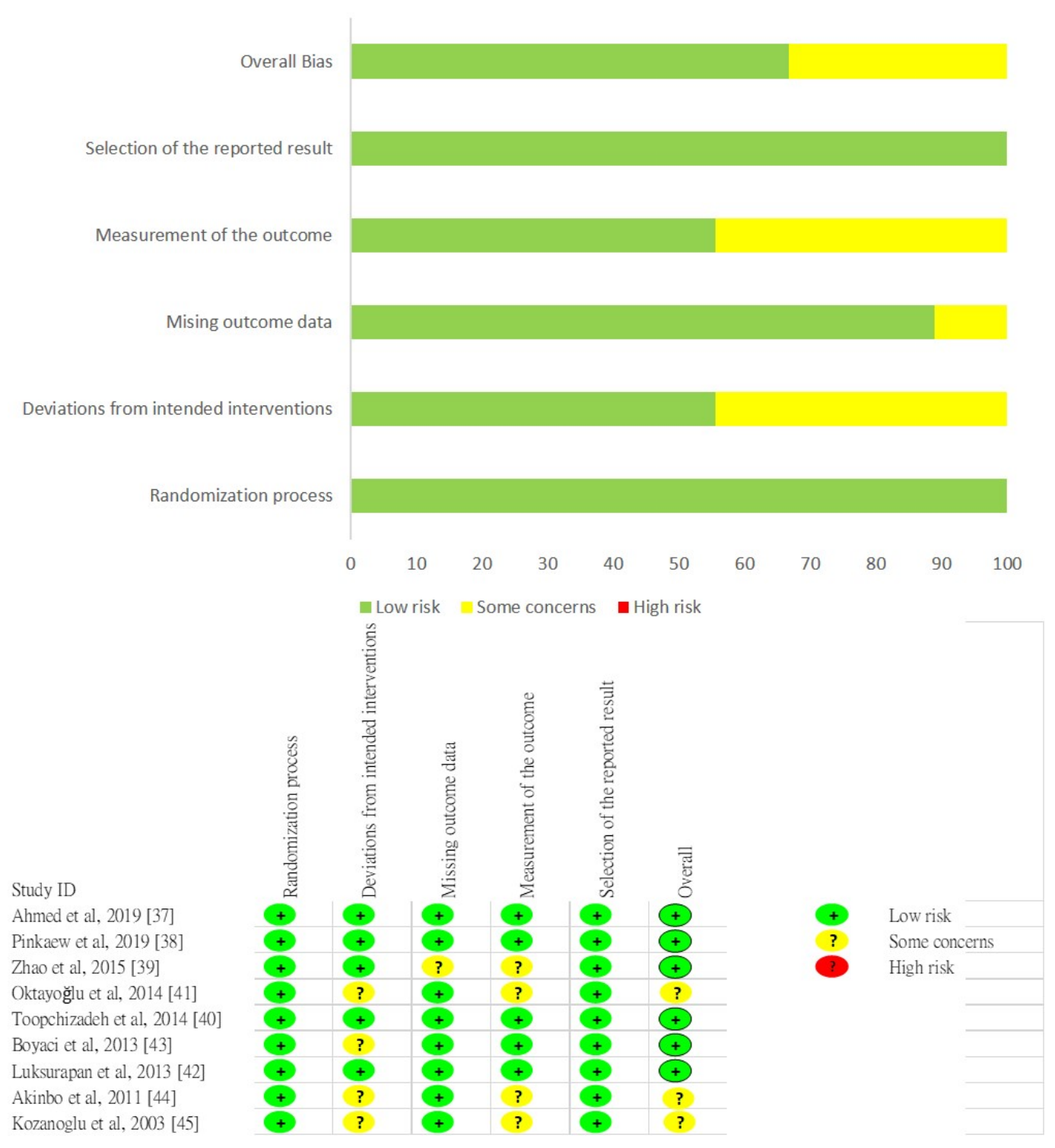

\section{Figure 2}

Study quality assessment.

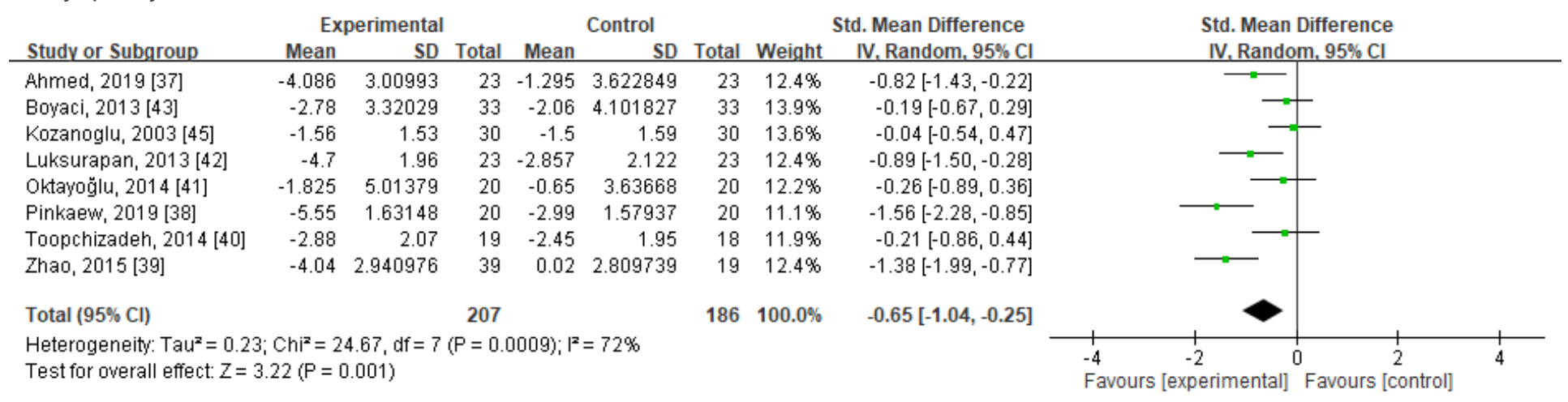

\section{Figure 3}

Forest plot for changes from baseline determined using the visual analog scale (VAS). 


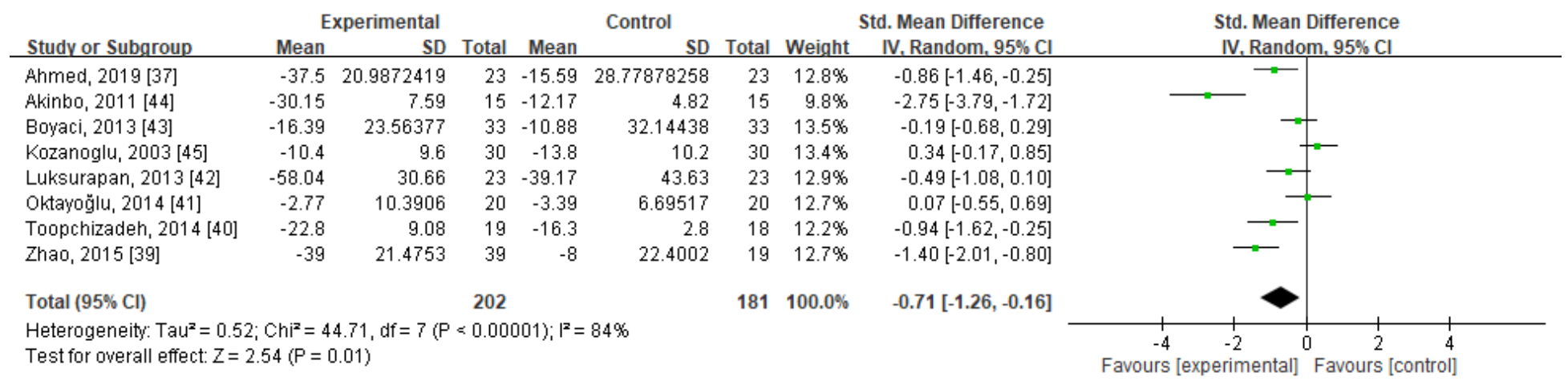

\section{Figure 4}

Forest plot for changes from baseline determined using the Western Ontario and McMaster Universities Arthritis Index (WOMAC).

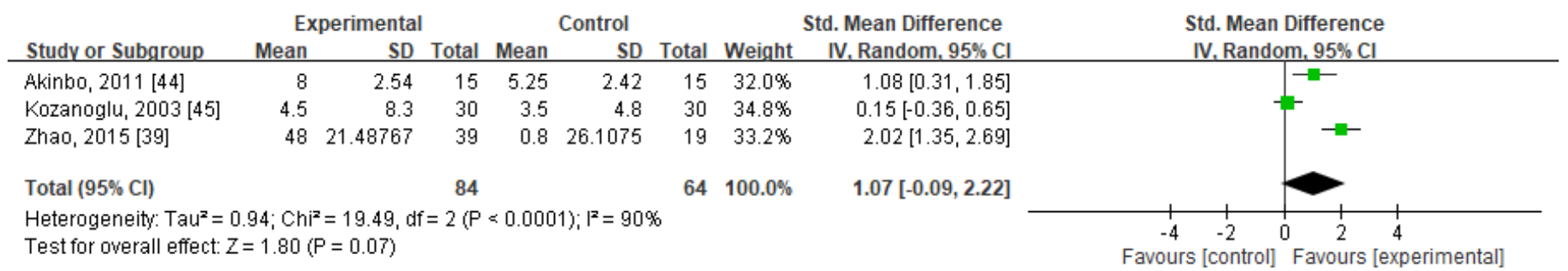

\section{Figure 5}

Forest plot for changes from baseline based on range of motion.

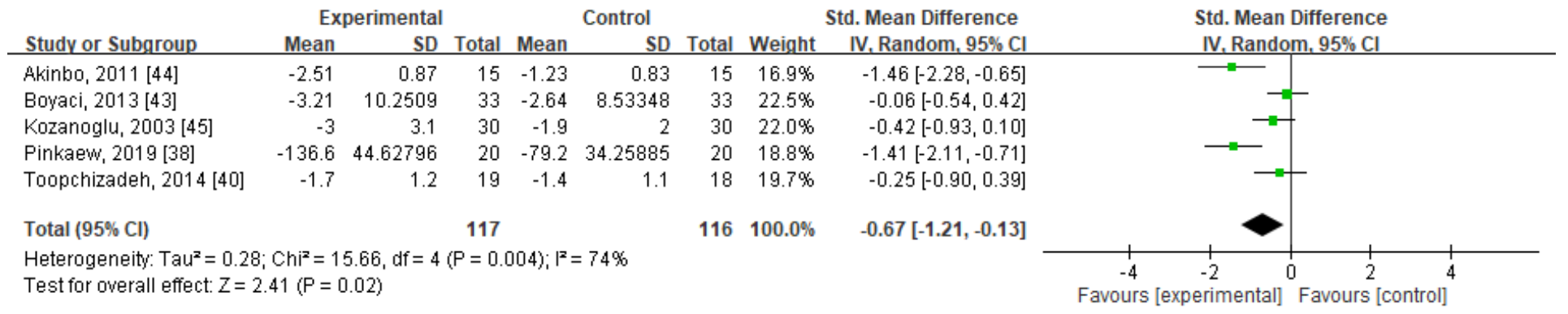

\section{Figure 6}

Forest plot for improvements in walk test scores.

\section{Supplementary Files}

This is a list of supplementary files associated with this preprint. Click to download.

- PRISMA2020checklist.docx

- appendix.docx 